\title{
A Content Analysis of the Counseling Literature on Technology Integration: American Counseling Association (ACA) Counseling Journals between 2000 and 2018
}

\author{
Hongryun Woo ${ }^{1} \cdot$ Ashley Dondanville ${ }^{1} \cdot$ Hansori Jang ${ }^{2} \cdot{\text { GoEun } \mathrm{Na}^{3} \cdot \text { Yoojin Jang }}^{4}$ \\ Published online: 16 July 2020 \\ (C) Springer Science+Business Media, LLC, part of Springer Nature 2020
}

\begin{abstract}
This content analysis provides an overview of articles specific to technology integration in the field of counseling published in American Counseling Association (ACA) journals between the years 2000 and 2018. In addition to the number of articles on this topic published during this time period, the study identified other aspects such as authors and institutional affiliations; methodology, study locations, and application settings; target populations and sample characteristics; and areas and types of technology integration. Recommendations are provided for counseling research in general and for future research extending from specific circumstances such as the COVID-19 pandemic.
\end{abstract}

Keywords Counseling journals $\cdot$ Content analysis $\cdot$ Technology $\cdot$ Counseling

Like other professions, counseling is experiencing a technological revolution, and advances in technology have increased the avenues available for counselors to meet the diverse needs of clients as well as counselor educators and those of counselors-in-training (Layne and Hohenshil 2005). As the use of technology and technological tools in counselor training and practice has evolved as a new dimension (Fenichel et al. 2002; Lewis et al. 2000), many counseling scholars (e.g., Carlson et al. 2006; Holmes and Foster 2012; Khelifa 2007) have begun to explore various topics related to technology integration in their research (e.g., ethical issues in online counseling, therapeutic outcomes with technology incorporated, counselors'

Hongryun Woo

h0woo001@louisville.edu

1 Department of Counseling and Human Development, University of Louisville, 326 Woodford R. and Harriett B. Porter Building, Louisville, KY 40292, USA

2 The University of Toledo, Toledo, $\mathrm{OH}$, USA

3 School of Education, Hunter College, New York, NY, USA

4 College of Education, Hanyang, University, Seoul, Republic of Korea 
approaches to technology, etc.). While the technology-integrated counseling literature appears to have increased in recent years (Richards and Vigano 2013), the current status and trends evident in the literature have not yet been studied. Furthermore, research is lacking in terms of questions arising regarding information on best practice models of technology integration in the field of counseling. The present study aimed to address this void by examining the technology-specific discussion within American Counseling Association (ACA) journals over the 19-year span from 2000 to 2018.

\section{The Use of Technology in the Field of Counseling}

Traditionally, counseling has been grounded in face-to-face and synchronized communications between counselors and their clients. According to the common factors view, some $30 \%$ of counseling outcomes are accounted for by the therapeutic relationship between the client and the counselor (Hubble et al. 1999). More recently, though, the concept of face-to-face practice has been challenged by those who have advocated for the use of diverse forms of technology in practice (Fenichel et al. 2002; National Board for Certified Counselors [NBCC], 2016). Their views have reflected a new model that includes the incorporation of technology into counselor training and practice, because of its availability, benefits and varied applications (Fenichel et al. 2002; Glasheen and Campbell 2009; Watts, 2002; Venne \& Doerr, 2018). Thus, there is now a growing consensus that counselor training and practice should be aligned with the utilization of technology (de la Varre et al. 2011; Dincyurek and Uygarer 2012; Glasheen et al. 2016; King et al. 2006; Menon and Rubin 2011).

Specifically, the expansive growth of computer and Internet-based technologies offers new alternatives for the delivery of counseling services (Watts, 2002). For clients, email-based counseling, chat-rooms, cybertherapy, online self-help and support groups, and numerous counseling information websites provide the convenience of professional services regardless of time and location (Barak and Grohol 2011). Internet-based counseling can be attractive and beneficial to many clients as it is likely to increase the ease of clients' access to resources; is less intimidating to certain client populations; is cost effective; and is suitable for those who live in remote areas and/or those who are unable to undertake face-to-face counseling for various reasons (de la Varre et al. 2011; Dincyurek and Uygarer 2012; King et al. 2006; Klein et al. 2010; Krist and Woolf 2011; Menon and Rubin 2011; Simpson et al. 2005).

For counselors, the need to incorporate technology in their work has also increased. For example, in the midst of the COVID-19 pandemic, conducting counseling sessions on-line (e.g., videoconferencing or web-based messaging) has become much closer to being standard practice, given the circumstances and the need to avoid risks of infection in the counseling office (Reidbord 2020). Technological advances being utilized by counselors relate directly to the various regular elements of counseling (National Board for Certified Counselors [NBCC], 2016). For example, technologies offer counselors several opportunities, including taking digitally-stored case notes, advertising counseling services to broader client populations, consulting with professional colleagues, even internationally, and receiving and sharing information via professional listservs (McFadden and Jencius 2000). Technologies also make it possible for counselors to provide and/or participate in distance education, on-line courses and presentations, web-based messaging, and videoconferencing (Shallcross 2011). As Baltimore (2001) asserted, it is indeed difficult to think of counselors without them using technology in some form in their practice. 
Counselor education programs are also increasingly required to adapt to the use of technology in student training and educational interactions (Carlisle et al. 2013; Watson 2003). For example, technology integration in counselor training offers alternative formats for supervision and case conferencing (Butler and Constantine 2006; Dudding and Justice 2004; Trolley and Silliker 2005). Cyber-supervision, which utilizes Internet video conferencing to supervise counselors-in-training, allows students and their supervisors to communicate in real time whenever it is convenient and/or advantageous (Conn et al. 2009). Similarly, webbased training of counseling supervisors on practicum and internship sites is another example. These involvements are cost effective and time saving and can be particularly useful to students and site supervisors who experience logistical difficulties, geographical limitations, and/or disabilities that interfere with traditional face-to-face supervision (Bacigalupe 2010; McAdams and Wyatt 2010; Perry, 2012; Rousmaniere and Frederickson 2013). In addition, advances in information and communication technology, in particular, have increased avenues for counseling programs to internationalize students' educational experiences through such initiatives as online exchange programs (Bhat and McMahon 2016).

Finally, the benefit of technology integrated into counseling includes its potential for use in research. The ease of collecting and storing data electronically allows researchers to more easily compile information to be used for counseling and supervision research. Also, the data collected from counseling practice could be used to establish the needed research and to evaluate effective and non-effective approaches in technology-mediated counseling (NBCC, 2001). As discussed so far, technology is coming to be used in every facet of counselor education and practice. This implies that it is important to prepare future counselors for the use of technology and to develop their technology competencies to effectively work with diverse client populations who may benefit from different forms of technology in counseling.

\section{Discussion of Technology Competences and Standards}

The increasing use of technology in the field of counseling has led to the development of counselor competency standards as well as ethical guidelines for the use of technology (Hines, 2002). Professional counseling organizations (e.g., ACA, 2014; the Council for Accreditation of Counseling and Related Educational Programs [CACREP], 2016; the Association for Counselor Education and Supervision [ACES], 1999; and the NBCC, 2001) have established and/or endorsed ethical as well as training standards for the integration of technology into counseling. For example, the NBCC has defined five different forms of distance counseling (i.e., telephonebased, email-based, chat-based, video-based, and social network-based services) and introduced ethical guidelines for distance counseling (NBCC, 2016). Similar to the NBCC's initiatives, the ACA published 'Ethical Guidelines for Internet On-Line Counseling' in 1999. Most recently, in the face of the COVID-19 global pandemic, the ACA ( 2020) organized resources and provided training sessions on ethical issues and considerations regarding the disease and telebehavioural health services (known as distance counseling).

While the NBCC and ACA focused their efforts on developing ethical guidelines for counseling practice, the ACES (2000) endorsed technical competency standards for counselor education programs for student training (http://www.acesonline.net/competencies.htm) as well as for online instruction. The technical competency standards include various topics that 
counseling students need to be familiar with by the completion of their program, such as computerized testing, productivity software, audiovisual equipment, computerized statistical packages, counseling-related data bases, email, and subscribing to listservs.

The counselor accreditation body, CACREP (2016), also includes in its standards technology competencies as an expectation for counseling graduates. For example, they clearly state that understanding technology's impact on the counseling profession is foundational knowledge required of all entry-level counseling graduates. CACREP also expects certain curriculum areas in counseling programs to specifically include technology-related issues. For example, courses on counseling and helping relationships should address "ethical and culturally relevant strategies for establishing and maintaining in-person and technology-assisted relationships" (p. 10), and "the impact of technology on the counseling process" (p.10).

Technology is also referenced under different specialty programs as an expectation for students (CACREP, 2016). According to the standards for clinical rehabilitation counseling programs, students should be knowledgeable about "assistive technology to reduce or eliminate barriers and functional limitations" for clients (p. 25). Courses on career development and career counseling should address "strategies to assist clients in the appropriate use of technology for career information and planning" (p. 25). Under the area of supervision for doctoral programs, students should have an opportunity to be familiar with "modalities of clinical supervision and the use of technology" (p. 34). As noted in many standards set by counseling associations, technology skills are important tools for counselor education and practice, and having technology competencies is becoming a clear expectation for counseling professionals.

\section{Purpose of this Study}

To date, no content analysis has examined technology-specific manuscripts in counseling journals, which restricts the opportunity to understand the trends of the literature on technology integration in the field of counseling. The current study aimed to fill this void by presenting an overview of content areas of technology-focused articles published in all counseling journals affiliated with the American Counseling Association (ACA). Specifically, in addition to commonly explored content themes, we focused on other distinctive content areas, such as areas of technology integration and types of technology used to provide more comprehensive understanding of the trends in technology research in counseling.

\section{Method}

\section{Research Team}

Our research team was comprised of two researchers. The first was an associate professor and the second a doctoral student at the same large Southern U.S. university. Both were experienced in qualitative research. The first researcher had conducted several qualitative research studies, including those involving content analyses, and the second had acquired skills in regard to content analysis research, including article searches, abstract and keyword screening processes, and data coding. The research team remained in contact at least once per week, via email or in-person meetings throughout the duration of the study. 


\section{Materials and Selection Criteria}

The current study sought to examine the content and methodologies of technology-integrated counseling articles published in all 21 peer-reviewed ACA journals as recorded on the ACA website (http://www.counseling.org) between 2000 and 2018. The journals selected for analysis were: the Journal of Counseling \& Development (JCD), the Adultspan Journal, the Career Development Quarterly (CDQ), the Counseling and Values Journal (CVJ), Counselor Education and Supervision (CES), the Journal of Addictions \& Offender Counseling (JAOC), the Journal of College Counseling (JCC), the Journal of Employment Counseling (JEC), the Journal of Humanistic Counseling (JHC), the Journal of Multicultural Counseling and Development (JMCD), Counseling Outcome Research and Evaluation (CORE), The Family Journal (TFJ), the Journal of Creativity in Mental Health (JCMH), the Journal of Military and Government Counseling (JMGC), the Journal of LGBT Issues in Counseling (JLGBT), the Journal for Social Action in Counseling in Psychology (JSCAP), the Journal of Mental Health Counseling (JMHC), the Rehabilitation Counseling Bulletin (RCB), the Journal for Specialists in Group Work (JSGW), Measurement and Evaluation in Counseling and Development (MECD), and Professional School Counseling (PSC).

Articles were obtained and analyzed for inclusion in the study by (a) using a keyword search in ERIC and PsycINFO first, and then (b) examining the abstracts of all articles published in the aforementioned journals. Specifically, the keyword search was performed with technology-related terms and definitions including: technology, assistive, integrative, virtual, virtual reality, computer, software, Internet, web, web-based, digital, media, simulated/simulation, on-line, phone, and electronic devices, counseling, therapy, psychotherapy, mental health, group, intervention, prevention, service, practice, supervision, training, education, school, clinic, agency, community, remote, self-help, support, resource, information, counselor, educator, therapist, professional, practitioner, and supervisor. These keywords were entered separately and also in combination (e.g., 'technology in group counseling, 'online supervision'). Articles were selected for inclusion based on their use of these keywords and their relation to counseling practices as well as to counselor education and supervision.

Furthermore, as a precaution against overlooking articles that might align with the purpose of the study, we reviewed the abstract, title, and keywords of every article published in the previously listed counseling journals. During this process, articles, including both research articles (i.e., involving data collection and analysis processes) and non-research articles, (i.e., involving literature reviews, introduction of theory and/or models, and case studies) were selected for inclusion. Conversely, items that were advertisements, association announcements, book reviews, commentaries or replies, guidelines for authors, and interview transcriptions were excluded from data analysis. Based on these criteria, the total number of selected articles was 80 out of 9066 articles published in the stated sources between 2000 and 2018.

\section{Procedures}

Prior to performing the analysis, we reviewed literature on content analyses (e.g., Arredondo et al. 2005; Blancher et al. 2010; Loveland et al. 2006; Smith et al. 2008; Yoon et al. 2011) to generate content areas and classifications for data coding and analysis. To begin, the first author reviewed the articles and formed the preliminary content categories. Next, a list of content areas was developed based on the literature (cf., Arredondo et al. 2005; Blancher et al. 2010; Loveland et al. 2006; Smith et al. 2008), which provided procedures and essential 
categories to be integrated in the content analyses. These content areas included authorship and author affiliation, research methodology, target populations and sample characteristics, and topics of interest.

Next, the second author assessed the results and documented any disagreement. Through the process of consensus building, as guided by the consensual qualitative research approach (CQR; Hill et al. 2005), inter-rater agreement between both authors was achieved. The CQR process is founded on the supposition that each member of a research team contributes to the investigative process with their distinctive knowledge, expertise, and perspectives concerning the classification and significance of data. As such, consensus was reached through collaborative discourse where both authors appreciated the other's professional experiences and unique perceptions. In these conversations, the researchers discussed their individual understandings of the data and achieved consensus, which resulted in cohesive content areas and themes for analysis.

In the process of reaching consensus, categories were expanded to incorporate two additional content areas, as they would aid in the understanding of research trends on technologyintegrated counseling and the extent to which the counseling profession emphasized such research. The additional content areas were: (a) the frequency with which technologyintegrated articles were published in the previously listed journals and (b) the types of technology integrated counseling practices described in each article. Then the researchers finalized content areas for analysis as follows: (a) the number of technology-integrated articles, (b) authors and institutional affiliations, (c) methodology, study locations, and application settings, (d) target populations and sample characteristics, and (e) areas and types of technology integration.

Next, we analyzed each article using these content areas. For the first content area, we quantified the number of total articles as well as technology-integrated counseling articles published in the 21 journals each year over the period concerned. The authors and institutional affiliations category was subcategorized according to the number of contributors in each article and the authors' institutional affiliations at the time of their study.

For the methodology content area, study designs were identified, which included quantitative, qualitative, mixed-methods, and conceptual designs. Articles were considered to have a conceptual design if they did not collect data, but they explored conceptual frameworks, integrative models, and reviews (Yadav, 2010). If the studies were empirical in nature, study locations were sub-grouped into career counseling centers, counseling clinics, counseling licensure boards, inpatient psychiatric units, international universities, K-12 school settings, online settings, U.S. universities, and others. Application settings for all articles were specified according to the settings where the study was applicable, such as counselor educators/supervisors, counselor training, institutional change, mental health practice, research, and teaching. Up to two application settings were assigned to each article.

The target populations content area was detailed into K-12 students, college students, counseling clients, counselors-in-training, counseling practitioners, counselor educators, and others. The category of sample characteristics, if empirical, was described with subcategories such as clinical human samples vs. non-clinical samples. Areas of technology integration were itemized with subcategories such as counseling, counselor training and supervision, assessment, psychoeducation, and others. Types of technology used were categorized into technological mediums including computer-based asynchronized messaging, phone-based verbal communication, computer-based video conferencing, phone-based messaging, etc. 
Throughout the process of coding and analysis, we utilized the summative content analysis technique to identify specific content areas in the articles (Hsieh \& Shannon, 2005). We began by independently coding and analyzing the data. To address any disagreements during the coding process, we communicated regularly with each other. When initial analyses were completed, we cross-checked the other's coding. In finalizing our content areas and coding, we came to a consensus through discussions.

\section{Results}

\section{The Number of Technology-Integrated Counseling Articles}

In the 21 ACA counseling journals, a total of 9537 articles were published between the years 2000 and 2018. Of these, $88(0.9 \%)$ focused on technology-integrated counseling. Among the 21 journals, the highest percentage of technology-integrated counseling articles were published by $C D Q(17 \%, n=15)$. The following percentages of technology-integrated counseling articles were $J S G W(10.0 \%, n=9), T F J(9.1 \%, n=8), P S C(9.1 \%, n=8), J M H C(8.0 \%$, $n=7), R C B(6.8 \%, n=6)$, and $J E C(6.8 \%, n=6)$. There were four journals in total that did not publish any technology-integrated counseling articles (i.e., JMCD, CORE, Journal of LGBT issues in Counseling, JSACP).

\section{Authors and Institutional Affiliations}

The 88 articles relevant for coding were written by 248 different authors. Of these articles, $22.7 \%$ were written by a single author $(n=20), 28.4 \%$ were dual-authored $(n=25), 21.6 \%$ included three authors $(n=19)$, and the remaining $27.3 \%$ were written by four or more authors $(n=24)$. The majority of the articles were written by first authors residing in the U.S. $(n=83)$. Of the first authors, $88.6 \%$ were associated with universities/colleges $(n=78) ; 3.4 \%$ were counselors in private practice $(n=3) ; 3.4 \%$ were directors of career development organizations $(n=3) ; 2.3 \%$ were school counselors $(n=2) ; 1.1 \%$ was a researcher at a private institute $(n=$ $1)$; and another $1.1 \%$ was a director of the counseling department at an online high school $(n=$ 1).

\section{Methodology, Study Locations, and Application Settings}

There were more articles written with an empirical approach $(59.1 \%, n=52)$ than a conceptual approach $(40.9 \%, n=36)$. Of the empirical articles, $48.1 \%$ were quantitatively oriented $(n=$ 25); $28.8 \%$ were qualitatively oriented $(n=15)$; and $23.1 \%$ used mixed-methods $(n=12)$. There were also trends in the methodology regarding data collection and methodology, which are also reported below.

Regarding the methodology of quantitative research, for data collection, $80.0 \%$ of these studies utilized surveys and questionnaires $(n=20)$ and $20.0 \%$ used pre- and post-test results $(n=5)$. In terms of data analysis, the quantitative articles used a variety of statistical data analysis methods including correlations, factor analysis, multiple regression analysis, ANOVA, MANOVA, Independent $t$-test, f-test, and Cohen's $d$ effect size indicator.

The qualitative articles utilized several methods for data collection. Of these articles, $40.0 \%$ utilized open-ended surveys and questionnaires $(n=6), 33.3 \%$ also used focus groups, 
interviews, and narratives $(n=5)$, and $26.7 \%$ utilized only interviews $(n=4)$. Regarding data analysis, the CQR or phenomenological approach was the most common method $(73.3 \%, n=$ 11). Other qualitative data analysis methods, such as emerging and cross-case patterns, constant comparative method, discriminant analysis, and theoretical schemes, were also used in seven articles (46.7\%). Percentages exceeded $100 \%$ because some articles used more than one data analysis method.

Of the 12 mixed-methods articles, 50.0\%, used open- and closed-ended surveys and questionnaires $(n=6) ; 33.3 \%$ used closed-ended surveys and questionnaires plus interviews $(n=4) ; 8.3 \%$ used closed-ended surveys and questionnaires plus focus groups $(n=1)$; and $8.3 \%$ used interviews $(n=1)$. Lastly, the mixed-methods articles employed frequencies, means, Chi Square, content themes, correlations, ANOVA, and qualitative coding in their data analysis.

Study locations of the empirical research articles were performed $38.5 \%$ of the time in virtual settings, collecting study data online only $(n=20), 30.8 \%$ at American Universities $(n=16), 15.4 \%$ in K-12 public schools $(n=8), 9.6 \%$ in counseling centers $(n=5), 1.9 \%$ at a career counseling board $(n=1), 1.9 \%$ in an inpatient psychiatric unit $(n=1)$, and, finally, $1.9 \%$ at a non-American university $(n=1)$. Regarding application settings, $72.7 \%$ of both conceptual and empirical articles were applicable to integrating technology into general mental health counseling practice $(n=64), 38.6 \%$ into counselor education and supervision $(n=34)$, and $6.8 \%$ into mental health counseling in K-12 settings $(n=6)$. Percentages reported exceeded $100 \%$ because some articles included more than one application setting.

\section{Target Populations and Sample Characteristics}

The target population for 31 out of the 88 articles was counseling practitioners (35.2\%). The second largest target population was counseling clients $(n=29,33.0 \%)$. Counselors-in-training made up the third largest population $(n=20,22.7 \%)$, followed by K-12 students $(n=10$, $11.4 \%)$, college students $(n=6,6.8 \%)$, and K-12 school counselors $(n=6,6.8 \%)$. A few articles also included counselor educators $(n=4,4.5 \%)$ and counseling licensure boards $(n=1$, $1.1 \%$ ) as the target population. Again, percentages exceeded $100 \%$ because some studies focused on multiple target populations.

In the 52 empirical studies, a total of 7559 participants were involved. Regarding sample characteristics, females represented the majority of participants in 32 studies $(61.5 \%)$, while males represented the majority in nine studies (17.3\%). Eleven studies $(21.2 \%)$ did not report gender information about participants. In terms of race/ethnicity, White/European Americans made up the majority of the samples in the empirical studies that provided information about the race/ethnicity of their particular sample $(n=34)$. Approximately 27 of the research articles (51.9\%) included some racial/ethnic minority participants (i.e., African Americans, Asians, and Hispanics/Latinos). Eighteen studies (34.6\%) did not provide information about the race/ ethnicity of their sample.

\section{Areas and Types of Technology Integration}

Areas of Technology Use The majority $(69.3 \%, n=61)$ of articles included in the analysis focused specifically on the use of technology-integrated practices in mental health counseling. Specifically, many articles addressed the use of technological resources in counseling. A common technological resource used for and during counseling was interactive technologies, 
including computer-based simulations and interactive journaling programs $(29.5 \%, n=26)$. Several articles also discussed websites as resources that could be used during counseling. These online resources included Internet resources for clients provided by practitioners $(12.5 \%, n=11)$, Internet resources for use by practitioners $(5.7 \%, n=5)$, and social media/ social networking $(5.7 \%, n=5)$.

Many articles also examined the use of technology in counselor education and supervision (18.2\%, $n=16)$, support/discussion groups $(13.6 \%, n=12)$, assessment $(10.2 \%, n=9)$, and psychoeducation $(5.7 \%, n=5)$. Additionally, several articles $(26.1 \%, n=23)$ measured practitioners' experiences with and perceptions of technology-integrated practices. Finally, there were articles $(23.9 \%, n=21)$ that suggested ethical implications associated with technologyintegrated counseling practices. Numbers exceeded 88 because some articles included more than one area of technology use.

Technological Mediums Many articles focused on the different mediums of technology that can be used in counseling, counselor education and supervision, support/discussion groups, assessment, and psychoeducation. These different technological mediums included, computerbased asynchronized messaging (e.g., email; 11,4\%, $n=10$ ), computer-based synchronized messaging (e.g. instant messaging; $9.1 \%, n=8)$, phone-based verbal communication $(6.8 \%$, $n=6$ ), computer-based video conferencing (e.g. Skype; $4.5 \%, n=4$ ), phone-based messaging (e.g., text messaging; $3.4 \%, n=3$ ), phone-based applications (e.g., iPhone applications; $2.3 \%$, $n=2)$, cinema-therapy $(2.3 \%, n=2)$, and computer-based audio conferencing $(1.1 \%, n=1)$.

\section{Discussion}

The purpose of this content analysis was to review the trends and themes of technology integration research in the field of counseling published in ACA journals between 2000 and 2018. We found a number of content areas with interesting findings. First of all, although more and more scholars (e.g., Brandt and Henning 2002; Sabella 2010; Tang 2003) emphasize the importance of integrating technologies into counselor training and practice, articles discussing technology integration in the field of counseling comprised only $0.9 \%$ of the articles published in ACA journals within the 19-year span. This finding clearly demonstrates the gap between the increasing interests and use of technology in counselor training and practice (e.g., Brandt and Henning 2002; Sabella 2010; Tang 2003) and the scarcity of technology-specific discussion published in counseling journals. It is possible that the lack of proactive measures on technology-integration (West 2012) and/or the difficulty faced when trying keep up with advances in technology present a challenge for generating technology-specific research. The limited number of publications on technology-integration, particularly the lack of empirical evidence regarding the effectiveness of technology use in counselor training and practice, might present a concern for counseling professionals who consider using or who have been active users of technology in counselor education and/or practice.

We hope that research on the utilization of technology in the field of counseling continues to grow and that more empirical studies, in particular, are conducted that demonstrate outcomes of technology integration into various areas in counseling (e.g., counseling approaches, interventions). Particularly, during a public health emergency such as the COVID-19 pandemic, counselors' technological competency in the delivery of distance counseling can be 
critical. More studies and publications on the use of technology and its effectiveness in regular counseling practice and in relation to particular crises are warranted.

In terms of authorship and institutional affiliations, the majority of the articles were written by two or more authors, which is similar to the findings of previous content analyses (e.g., Woo et al. 2016; Woo \& Neo, 2013). Also, like many other content analyses in counseling (e.g., Erford et al. 2011; Woo \& Neo, 2013), we found that most of the leading authors of the studies analyzed were affiliated with universities/colleges, while only a few were counseling practitioners affiliated with private counseling clinics. This is an interesting finding given that the main target populations and participants of the empirical studies included in the analysis were counseling practitioners. Topics of technology-integration, such as counselor competencies using technologies, perceptions and/or effects of online counseling, training effects on the use of technologies in practice, could have benefited from research collaborations between researchers and field-based counseling professionals. In addition, given the fact that telemental health options have significantly exploded during the coronavirus pandemic and that it has been essential for counseling practitioners to provide more accessible mental health treatment from face-to-face services to virtual ones (Ali 2020), it is our hope that more practitioner-led studies and/or research from practitioners' perspectives will be conducted on the topics of technology integration.

Regarding the types of methodology, descriptive approaches were more common than other methods in technology-specific studies. Of the empirical studies, quantitative methods were more frequently used than qualitative methods, and the studies using quantitative methods collected the data most commonly via survey. This may be because surveys are much easier than other quantitative methods in gathering data from large samples in a short period of time (Hew et al. 2007). As the role of evidence-based practice (EBP) has continuously gained emphasis in the counseling field (Heppner et al. 2008), it is our hope that more empirical studies would examine counseling interventions integrating technologies and their effectiveness. In regard to the study locations in which research was conducted, findings showed that university settings outnumbered any other settings such as K-12 schools. This finding is consistent with that of previous technology-focused content analysis in other fields (e.g., Hew et al. 2007). It is possible that the majority of the authors were affiliated with universities as faculty members or graduate students; thus, it might have been easier for them to utilize preestablished relationships and connections to universities in conducting research and collecting data. Difficulties in getting parental consents and/or getting school administrators on board, frequently mentioned as a challenge when conducting research in K-12 school settings, might be another possible reason.

For sample characteristics, about $70 \%$ of the samples in the empirical studies consisted of non-clinical samples, such as counselors-in-training, counseling practitioners and counselor educators, while about $30 \%$ were individuals in clinical settings (e.g., counseling clients). This finding is interesting given that it is critical for the field of counseling, as a whole, to establish an understanding of how counseling clients respond to technology-integrated counseling services and how counseling strategies and interventions with specific technological mediums work for different clients in order to support EBP. Research exploring the effectiveness of these counseling approaches for different clientele should be encouraged.

White/European Americans represented the largest sample size in empirical studies. Like other content analyses (Nilsson et al. 2007; Smith et al. 2008), ethnic minority groups were underrepresented in technology-integration studies. Telehealth technology could be a viable mode of mental health service delivery to those in ethnically, culturally, and/or linguistically 
underserved populations (Jang et al. 2014); thus, more inclusion of minority samples is needed in research of technology integration.

Results showed that where technologies were used and what types of technologies were employed were two major topics. Using technologies as resources in mental health counseling was the most prominent theme within the first main topic of interest, which possibly reflects the call for increased consideration for technology as a useful communication tool and resource when counseling clients (e.g., Paisley and McMahon 2001; Van Horn and Myrick 2001). In addition, a wide variety of technologies were used in various areas, such as counseling practice, counselor training and supervision, support/discussion groups, assessment, and psychoeducation. It is encouraging that various forms of technologies have been examined even with a relatively small number of articles published. It is our hope that more research studies will be conducted on the various settings and areas within which technologies can be utilized (e.g., counseling clients with disabilities; multidisciplinary settings) and on the newest forms of technologies used in counseling that can inform the latest clinical perspectives.

\section{Implications for Counseling Research}

The current investigation aimed to provide counseling researchers, practitioners, and educators with an accurate representation of the status of technology-integrated literature in the field of counseling over recent years. From our content analysis, several important implications were drawn. First, despite the skyrocketing rate of technology use in our daily lives, and in virtual mental health services in particular, the frequency of publications on technology use in counseling journals is disproportionately limited. According to the Pew Research Center (2018), 95\% of Americans now own a cellphone and $73 \%$ own a laptop or computer. In other words, the majority of Americans and many others around the world have access to technological mediums through which they could receive counseling services. However, of all the articles published in the 21 counseling journals we examined, less than $3 \%$ included a discussion of technology-integrated practices.

Accounting for the increasing ownership of and access to technology, more research is needed on the efficacy of technology-integrated methods in both counseling practice and counselor education. For example, a global pandemic, as is the case with COVID-19, presents counseling practitioners with extra challenges. They need not only offer counseling remotely, but also do so taking into consideration constantly changing contexts and consequences of the ongoing crisis. Keeping confidentiality in distance counseling during such circumstances can be extra challenging as physical separation from family members at home may be difficult to manage and to apply safeguarding policies (Tip 2020). Under these circumstances, information on how to conduct or improve distance counseling and what methods to use to best deliver it to diverse clients in urgent need is extremely important. With more attention given to and research undertaken on such practice guidelines and methods, the use of them can become more refined, effective and helpful to clients, counseling students, and practitioners. Thus, the current analysis highlights the importance of future studies for examining technologyintegrated elements so as to keep the field of counseling on par with the increasingly pervasive nature of technology in the world today.

Second, current research on technology-integration in the field of counseling lacks representation from racially and ethnically diverse populations. While there were a few articles that 
focused on Asian American and Asian international college students, the majority of participants in the other studies were White/European Americans. However, other racial/ethnic groups could greatly benefit from inclusion in this research. Studies indicate that nonEnglish speaking Asians and Latinos (Sentell et al., 2007) and Blacks/African Americans living in high poverty neighborhoods (Denton and Anderson 2005) have limited access to mental health care. Given that technology serves as a potential mechanism for providing services to those with limited access to traditional mental health services and the poor access that has been reported among certain racial/ethnic groups, more inclusive research is needed.

Third, the vast majority of first authors who published about technology-integration were affiliated with universities. Therefore, fewer articles were published by non-academics, such as counselors or staff in counseling centers or K-12 educational settings. Even though the majority of authors were associated with universities, most of the articles were focused on the use of technology-integrated methods in mental health counseling. Thus, the current literature on technology-integration may be less representative of counseling professionals' field experiences. Accounting for this possibility, we suggest that non-academics become more involved in technology-integrated research to ensure that their unique perspectives are represented.

Lastly, the ethics of technology-integration in the field of counseling was mentioned as a key topic of interest in a quarter of the articles included in our analysis. The frequency of the discussion of the ethical use of technology in these articles highlights a potential concern for how technology can best be used in accordance with the ACA Code of Ethics (ACA, 2015). Specifically, these articles considered ethical issues such as access, assessment, confidentiality, data storage, informed consent, multiple relationships, professional competence, records and security. Many of the articles that expressed ethical concerns were literature reviews and conceptual pieces, rather than empirical research articles. Thus, we assert that more empirical research is needed on the ethical implications and guidelines of using technology to deliver counseling services and to educate and/or supervise counselors and counseling students. Furthermore, more empirical research is needed because the variety of technological mediums that can be used in counseling (i.e., text messaging, emails, Skype) each present unique ethical considerations and potential pitfalls. For example, the use of email presents different ethical concerns than videoconferencing methods such as Skype, especially regarding security and data storage.

Additionally, in accordance with the implications provided by other researchers (i.e., Carlisle et al., 2017), we also recommend that future researchers develop an instrument to assess the competence of counselors to utilize technology-integrated methods in accordance with ACA standards. Assessing technology competency can be particularly critical for practitioners providing distance counseling services for the first time. With our recommendations for future empirical research on the ethical use of technology-integration with various technological mediums and the development of an instrument to assess the ethical competence to use technology-integrated methods, we hope that more clear expectations for the ethical use of technology will be created in the field of counseling.

\section{Compliance with Ethical Standards}

Conflict of Interest The authors declared that they have no conflict of interest. 


\section{References}

Ali, S. (2020, April 06). Telemental health during the coronavirus pandemic. Received from https://www. psychologytoday.com/us/blog/modern-mentality/202004/telemental-health-during-the-coronaviruspandemic

American Counseling Association. (2014). ACA code of ethics. Alexandria, VA: Author.

American Counseling Association (2020). COVID-19 and Telebehavioral Health: Ethical Considerations During a Public Health Emergency. https://aca.digitellinc.com/aca/conferences/89/view

Arredondo, P., Rosen, D. C., Rice, T., Perez, P., \& Tovar-Gamero, Z. G. (2005). Multicultural counseling: A 10year content analysis of the journal of counseling \& development. Journal of Counseling \& Development, $83,155-161$.

Association for Counselor Education and Supervision. (1999). Technical competencies for counselor education students: Recommended guidelines for program development. Retrieved from http://www.acesonline. net/competencies.htm

Bacigalupe, G. (2010). Supervision 2.0: E-supervision a decade later. Family Therapy Supervisor Bulletin, 9(1), $38-41$.

Baltimore, M. (2001). Recent trends in advancing trends in counselor education. Journal of Technology in Counseling, 2(2), 1-2.

Barak, A., \& Grohol, J. (2011). Current and future trends in internet-supported mental health interventions. Journal of Technology in Human Services, 29(3), 155-196. https://doi.org/10.1080/15228835.2011.616939.

Bhat, C. S., \& McMahon, M. (2016). Internationalization at home for counseling students: Utilizing technology to expand global and multicultural horizons. International Journal for the Advancement of Counselling, 38(4), 319-329.

Blancher, A. T., Buboltz, W. C., \& Soper, B. (2010). Content analysis of the journal of counseling \& development: Volumes 74 to 84. Journal of Counseling \& Development, 88, 139-145.

Brandt, D., \& Henning, K. (2002). Information and communication technologies: Perspectives and their impact on society. AI \& SOCIETY, 16(3), 210-223.

Butler, S. K., \& Constantine, M. G. (2006). Web-based peer supervision, collective self-esteem and case conceptualization ability in school counselor trainees. Professional School Counseling, 10(2), 146-152.

Carlisle, R. M., Carlisle, K. L., Hill, T., Kirk-Jenkins, A. J., \& Polychronopoulos, G. B. (2013). Distance supervision in human services. Journal of Human Services, 33, 19-31.

Carlisle, R. M., Hays, D. G., Pribesh, S. L., \& Wood, C. T. (2017). Educational technology and distance supervision in counselor education. Counselor Education and Supervision, 56(1), 33-49.

Carlson, L. A., Portman, T. A. A., \& Bartlett, J. R. (2006). Professional school counselors' approaches to technology. Professional School Psychology, 9, 252-256.

Conn, S. R., Roberts, R. L., \& Powell, B. M. (2009). Attitudes and satisfaction with a hybrid model of counseling supervision. Journal of Educational Technology \& Society, 12(2), 298-306.

Counsel for Accreditation of Counseling and Related Educational Programs. (2015). 2016 CACREP standards. Retrieved from http://www.cacrep.org/

de la Varre, C., Keane, J., \& Irvin, M. J. (2011). Enhancing online distance education in small rural US schools: A hybrid, learner-centered model. Journal of Asynchronous Learning Networks, 15(4), 35-46. https://oi. org/10.1080/09687769.2010.529109.

Denton, N. A., \& Anderson, B. J. (2005). Poverty and race research action council analysis of U.S. census bureau data. The Opportunity Agenda. Retrieved from http://www.opportunityagenda.org.

Dincyurek, S., \& Uygarer, G. (2012). Conduct of psychological counseling and guidance services over the internet: Converging communications. Turkish Online Journal of Educational Technology, 11(3), 77-81.

Dudding, C., \& Justice, L. (2004). A model for e-supervision: Videoconferencing as a clinical training tool. Communication Disorders Quarterly, 25(3), 145-151.

Erford, B. T., Miller, E. M., Schein, H., McDonald, A., Ludwig, L., \& Leishear, K. (2011). Journal of counseling \& development publication patterns: Author and article characteristics from 1994 to 2009. Journal of Counseling \& Development, 89, 73-80. https://doi.org/10.1002/j.1556-6678.2011.tb00062.x.

Fenichel, M., Suler, J., Barak, A., Zelvin, E., Jones, G., Munro, K., Meunier, V., \& Walker-Schmucker, W. (2002). Myths and realities of online clinical work: Observations on the phenomena of online behavior, experience, and therapeutic relationships: A third year report from ISMHO's clinical case study group. Retrieved from http://www.fenichel.com/myths/

Glasheen, K., \& Campbell, M. (2009). The use of online counselling within an Australian secondary school setting: A practitioner's viewpoint. Counselling Psychology Review, 24(2), 42-51.

Glasheen, K. J., Shochet, I., \& Campbell, M. A. (2016). Online counselling in secondary schools: Would students seek help by this medium? British Journal of Guidance \& Counselling, 44(1), 108-122. https://oi. org/10.1080/03069885.2015.1017805. 
Heppner, P. P., Wampold, B. E., \& Kivlighan, D. M. (2008). Research design in counseling (3rd ed.). Belmont, CA: Thomson Higher Education.

Hew, K. F., Kale, U., \& Kim, N. (2007). Past research in instructional technology: Results of a content analysis of empirical studies published in three prominent instructional technology journals from the year 2000 through 2004. Journal of Educational Computing Research, 36(3), 269-300.

Hill, C. B., Knox, S., Thompson, B. J., Williams, E., Hess, S. A., \& Ladany, N. (2005). Consensual qualitative research: An update. Journal of Counseling Psychology, 52, 196-205.

Hines, P. (2002). Student technology competencies for school counseling programs. Journal of Technology in Counseling, 2(2). Retrieved from http://jtc.colstate.edu/vol2_2/hines/hines.htm.

Holmes, C., \& Foster, V. (2012). A preliminary comparison study of online and face-to-face counseling: Client perceptions of three factors. Journal of Technology in Human Services., 30(1), 14-31. https://doi. org/10.1080/15228835.2012.662848.

Hsieh, H., \& Shannon, S. E. (2005). Three approaches to qualitative content analysis. Qualitative Health Research, 15(9), 1277-1288.

Hubble, M. A., Duncan, B. L., \& Miller, S. D. (1999). Introduction. In M. A. Hubble, B. L. Duncan, \& S. D. Miller (Eds.), The heart and soul of change: What works in therapy (pp. 1-19). Washington, DC: American Psychological Association.

Jang, Y., Chiriboga, D. A., Molinari, V., Roh, S., Park, Y., Kwon, S., \& Cha, H. (2014). Telecounseling for the linguistically isolated: A pilot study with older Korean immigrants. Gerontologist, 54(2), 290-296.

Khelifa, M. (2007). Online counseling: Competing ethically and safely in a global environment. American Association of Behavioral and Social Sciences, 10, 1-13.

King, R., Bambling, M., Lloyd, C., Gomurra, R., Smith, S., Reid, W., \& Wegner, K. (2006). Online counselling: The motives and experiences of young people who choose the internet instead of face to face or telephone counselling. Counselling \& Psychotherapy Research, 6(3), 169-174. https://doi.org/10.1080 $/ 14733140600848179$.

Klein, B., White, A., Kavanagh, D., Shandley, K., Kay-Lambkin, F., Proudfoot, J., \& Young, R. (2010). Content and functionality of alcohol and other drug websites: Results of an online survey. Journal of Medical Internet Research, 12, e51. https://doi.org/10.2196/jmir.1449.

Krist, A. H., \& Woolf, S. H. (2011). A vision for patient-centered health information systems. JAMA: Journal of the American Medical Association, 305, 300-301. https://doi.org/10.1001/jama.2010.2011.

Layne, C. M., \& Hohenshil, T. H. (2005). High tech counseling: Revisited. Journal of Counseling and Development, 83(2), 222-226.

Lewis, J., Coursol, D., Khan, L., \& Wilson, A. (2000). Life in a dot com world: Preparing counselors to work with technology. (ERIC documentation reproduction service no. ED449410).

Loveland, J., Buboltz, W., Schwartz, J, \& Gibson,G. (2006). Content analysis of CDQ from 1994-2003: Implications and trends for practitioners and researchers from a decade of research. The Career Development Quarterly, 54, 256-264.

McAdams, C. R., \& Wyatt, K. L. (2010). The regulation of technology-assisted distance counseling and supervision in the United States: An analysis of current extent, trends, and implications. Counselor Education and Supervision, 49(3), 179-192.

McFadden, J., \& Jencius, M. (2000). Using cyberspace to enhance counselor's cultural transcendence. In J. W. Bloom \& G. R. Walz (Eds.), Cybercounseling and cyber learning: Strategies and resources for the Millenium. American Counseling Association: Alexandria, VA.

Menon, G. M., \& Rubin, M. (2011). A survey of online practitioners: Implications for education and practice. Journal of Technology in Human Services, 29(2), 133-141. https://doi.org/10.1080/15228835.2011.595262.

National Board of Certified Counselors. (2001). The practice of internet counseling. Greensboro, NC: NBCC. www.nbcc.org/Assets/Ethics/nbcccodeofethics.pdf.

National Board for Certified Counselors, Inc. (2016). NBCC policy regarding the provision of distance professional services. Retrieved from ht t p s:// w w w $\mathrm{nbcc}$. org/Assets/Ethics/NBCCPolicyRegardingPracticeofDistanceCounselingBoard.pdf

Nilsson, J. E., Love, K. M., Taylor, K. J., \& Slusher, A. L. (2007). A content and sample analysis of quantitative articles published in the journal of counseling \& development between 1991 and 2000. Journal of Counseling \& Development, 85, 357-363.

Paisley, P., \& McMahon, H. (2001). School counseling for the 21st century: Challenges and opportunities. Professional School Counseling, 5(2), 106.

Perry, C. (2012). Constructing professional identity in an online graduate clinical training program: Possibilities for online supervision. Journal of systemic Therapies, 31, 53-67.

Pew Research Center: Internet and Technology Mobile Fact Sheet. (2018, February 05). Retrieved from http://www.pewinternet.org/fact-sheet/mobile/\#. 
Reidbord, S. (2020, April 05). Online therapy revisited, thanks to COVID-19. Psychology Today. https:/www. psychologytoday.com/us/blog/sacramento-street-psychiatry/202004/online-therapy-revisited-thanks-covid19

Richards, D., \& Vigano, N. (2013). Online counseling: A narrative and critical review of the literature. Journal of Clinical Psychology, 68(9), 994-1011. https://doi.org/10.1002/jclp.21974.

Rousmaniere, T., \& Frederickson, J. (2013). Internet-based one-way mirror supervision for advanced psychotherapy training. The Clinical Supervisor, 32(1), 40-55. https://doi.org/10.1080/07325223.2013.778683.

Sabella, R. A. (2010). School counselors perceived importance of counseling technology competencies. Computers in Human Behavior, 26(4), 609-617.

Sentell, T., Shumway, M., \& Snowden, L. (2007). Access to mental health treatment by english language proficiency and race/ethnicity. Journal of General Internal Medicine, 22(2), 289-293.

Shallcross, L. (October, 2011). Finding technology's role in the counseling relationship. Counseling Today, p. 26.

Simpson, S., Bell, L., Knox, J., \& Mitchell, D. (2005). Therapy via videoconferencing: A route to client empowerment. Clinical Psychology and Psychotherapy, 12, 156-165. https://doi.org/10.1002/cpp.436.

Smith, S. D., Ng, K., Brinson, J., \& Mityagin, E. (2008). Multiculturalism, diversity, and social advocacy: A 17year content analysis of counselor education and supervision. Counselor Education \& Supervision, 47, 249 263.

Tang, M. (2003). Career counseling in the future: Constructing, collaborating, advocating. The Career Development Quarterly, 52(1), 61-69.

Tip, L. (2020, May 04). Guidance for online therapy during COVID-19. National Elf Service. https://www. nationalelfservice.net/treatment/digital-health/online-therapy-during-covid-19/

Trolley, B., \& Silliker, A. (2005). The use of webCT in the supervision of counseling interns. Journal of Technology in Counseling, 4(1). Retrieved from http://jtc.colstate.edu/Vol4_1/Trolley/Trolley.htm

Van Horn, S. M., \& Myrick, R. D. (2001). Computer technology and the $\overline{2} 1$ st century school counselor. Professional School Counseling, 5(2), 124-131.

Venne, V., \& Doerr, M. (2018). Introduction to the "Technology in Practice" Special Issue. Journal of Genetic Counseling, 27, 317-319.

Watts, A. G. (2002). The role of information and communication technologies in integrated career information and guidance systems: A policy perspective. International Journal for Educational and Vocational Guidance, 2(3), 139-155.

Watson, J. C. (2003). Computer-based supervision: Implementing computer technology into the delivery of counseling supervision. Journal of Technology in Counseling, 3(1), 1.

West, D. (2012). Big data for education: Data mining, data analytics, and web dashboards. Brookings Institute.

Woo, H., Goo, M., \& Lee, M. (2016). A content analysis of research on disability: American counseling association journals between 2003 and 2013. Journal of Multicultural Counseling \& Development, 44, $228-244$.

Woo, H., \& Heo, N. (2013). A content analysis of qualitative research in select ACA journals (2005-2010). Counseling Outcome Research and Evaluation, 4(1), 13-25.

Yoon, E., Langrehr, K., \& Ong, L. Z. (2011). Content analysis of acculturation research in counseling and counseling psychology: A 22-year review. Journal of Counseling Psychology, 58(1), 83-96.

Publisher's Note Springer Nature remains neutral with regard to jurisdictional claims in published maps and institutional affiliations. 